\title{
"SOMOS RESTO DE GENTILES": EL MANEJO DEL TIEMPO Y LA CONSTRUCCIÓN DE DIFERENCIAS ENTRE COMUNIDADES ANDINAS ${ }^{1}$
}

\author{
José Luis Martínez ${ }^{2}$
}

\section{* Introducción}

Resumen

Las comunidades vecinas de Toconce, Ayquina y Caspana en el río Salado (II región, Chile) comparten un mismo espacio regional, un conjunto de prácticas productivas y similares estructuras sociopolíticas. Sin embargo, difieren en los relatos acerca de sus orígenes y ser "restos de gentiles" - esto es, prehispánicos- o bien, más modernos. Se propone que estas distintas narrativas, que no corresponden a lo mostrado por la arqueología, son resultado de un uso simbólico del tiempo, como significante de diferencias identitarias locales.

Palabras claves: atacameños - identidades - memoria - tiempo.

Abstract

The communities of Toconce, Caspana, and Ayquina in the Salado

River Valley (II región, Chile) share the same area, a similar set of production practices and sociopolitical structures. However, differ in the stories about their origins and their position between being "restos de gentiles" - that is, prehispanic - or more recent "modernities". Here, I propose that these narratives, which do not correspond to archaeological evidence, are the result of a symbolic use of time, as a signifier of different local identities.

Key words: atacameño - identities - memory - time. Recibido: octubre 2008. Aceptado: agosto 2009.
En el norte de Chile, desde la costa del océano Pacífico hacia las tierras del interior, se ubica el árido desierto de Atacama (Weischert 1975). Aprovechando una ruptura del cordón cordillerano andino, el desierto trepa hasta $3000 \mathrm{~m} . \mathrm{snm}$. Pocas ciudades se encuentran en este difícil espacio: Antofagasta, en la costa, y el enclave minero de Calama, próximo a las grandes minas de cobre de Chuquicamata y Radomiro Tomic. Las comunidades indígenas se concentran en el interior, unas en la cuenca del Salar de Atacama y de sus oasis, ubicados a $2500 \mathrm{~m}$.snm y las restantes en la cuenca del río Loa, en las nacientes de las quebradas altas (entre 3300 y 3500 $\mathrm{m} . \mathrm{snm}$ ) que dan origen a los escasos cursos de agua que desembocan en los oasis o en el mar. Son comunidades que tradicionalmente han sido descritas como atacameñas, aun cuando ha existido históricamente una importante presencia de otros grupos que, como los aymara de Arica y Tarapacá, y los lipes y chichas de Bolivia, han llegado permanentemente a la zona.

Tanto la arqueología (Aldunate y Castro 1981; Castro et al. 1984; Aldunate et al. 1986, entre otros), como la etnohistoria (Hidalgo 1978, 1985; Martínez 1998; entre otros) han mostrado que el poblamiento humano en la región atacameña ha sido, desde muchos siglos atrás, un mosaico cultural en el que han confluido colectivos

1 Este trabajo es resultado del Proyecto FONDECYT 1050143: "Identidades sociales en Tarapacá. Conflictos interétnicos y nacionalismos en la sociedad regional contemporánea”. Fue presentado en el $52^{\circ}$ Congreso Internacional de Americanistas (Sevilla 2006) y publicado en francés con el título "Nous sommes un reste des gentils. Le maniement du temps et la construction des differences entre trois comunautés andines (Chili)". En Pour une historie souterraine des Amériques: Jeux de memoires, enjeux d'identités, A. Ariel de Vidas (Coord.), pp. 101-124. L'Harmattan, París. Este texto es una traducción del original que incorpora párrafos que no estaban en la versión inicial, como también las sugerencias de los evaluadores.

2 Centro de Estudios Culturales Latinoamericanos, Departamento de Ciencias Históricas, Universidad de Chile. Casilla 73, Santiago, CHILE. Email:jmartine@uchile.cl; jomarcer@gmail.com. 
provenientes de regiones vecinas como Tarapacá, el Noroeste Argentino (incluyendo los Valles Calchaquíes y las tierras bajas de Tucumán) y el altiplano boliviano. La circulación de poblaciones, ideas, artefactos culturales y recursos no se detuvo con la imposición de la sociedad colonial. Las alianzas entre personas pertenecientes a distintos grupos étnicos coloniales y la dispersión de la población en una vasta región que incluía los corregimientos de Tarapacá (Audiencia de Lima), Carangas, Lípez y Chichas (Audiencia de Charcas) y localidades de la Gobernación de Tucumán (particularmente de la Puna atacameña y de los territorios de Jujuy y Salta), han sido ampliamente demostradas (Cajías 1975; Gentile 1986; Martínez et al. 1991; Sanhueza 1992; Martínez 1998; Hidalgo 2004).

Posteriormente, al producirse a principios del s. XX la demarcación definitiva de la línea de frontera entre Bolivia y Chile, el Estado chileno desarrolló una activa campaña, presionando a los lugareños para que se definieran como chilenos y borraran sus vínculos anteriores. ${ }^{3}$ Despues, las comunidades vivieron otros dos momentos en que se incrementaron la presencia estatal y las presiones por introducir un discurso único, "chileno", que desconocía los procesos históricos, comunitarios e identitarios locales. Primero, en la década de 1960, con la implantación de las escuelas y luego entre los años 1973 y 1990, durante los momentos de conflicto con Argentina y Bolivia. Sin embargo, los signos de los discursos de ambos momentos fueron distintos. Mientras en los años 60 se insistía en una historia nacional única, en la cual ni las comunidades indígenas ni sus identidades eran mencionadas (solo se hablaba de españoles, mapuche, y algo de los incas) en los años de la dictadura militar ese discurso fue contrapesado con una vigilancia que posicionaba a las comunidades "indios", marcando fuertes diferencias con otras sociedades.

Actualmente, estas poblaciones están bajo otras presiones: el desarrollo de un importante polo turístico internacional, ${ }^{4}$ y la lucha por el control de recursos tan

3 En un trabajo anterior (Martínez 1994) mostré detalles de ese proceso, que implicó, entre otras situaciones la progresiva clandestinización de los vínculos y de los viajes realizados hacia ambos lados de la nueva frontera. Ver también Sanhueza (2001).

4 El desarrollo turístico se ha centrado principalmente en el pueblo de San Pedro de Atacama, en el sector del salar del mismo nombre, vitales como el agua. ${ }^{5}$ A esto se agregan las tensiones de un sostenido proceso de revitalización de identidades -en especial desde que se dictó en 1993 la Ley 19253. conocida como Ley Indígena-, marcadas por una hegemonía creciente de quienes se autoreconocen como atacameños y por una burocracia indígena que orienta muchos de sus programas de apoyo y desarrollo social a partir de esa condición. Esto ha generado presiones para que todos se identifiquen como tales en perjuicio de otras definiciones que formaban parte de las posibilidades estratégicas locales hasta hace algunos años. Por ejemplo, no sentirse atacameños (ser atacameños, quedaba para los habitantes de San Pedro de Atacama y no para todo el conjunto), o definirse únicamente como habitantes de una comunidad o una localidad sin otros vínculos o, finalmente, decidirse por remarcar los orígenes, en cuyo caso se podría ser boliviano, argentino, oriundo de Pica (en Tarapacá) o de otros sitios que remitían invariablemente a otras historias, otras alianzas y distintas experiencias.

Estos procesos han sido interpretados como si se tratara únicamente de una cuestión de etnicidades, aspecto que quisiera discutir aquí a partir del trabajo de Wachtel (1992) sobre las identidades colectivas. Wachtel llamó la atención acerca de la necesidad de distinguir entre posibles identidades étnicas e "identidades colectivas", de dimensiones más locales, surgidas de los procesos coloniales y -me gustaría agregar- de procesos más tardíos como los republicanos. De los muchos elementos aportados por ese texto, me interesa destacar las nociones de contemporaneidad y de localidad de las identidades puesto que, por una parte, están siendo constantemente definidas y puestas en juego a partir de las presiones vividas interna y externamente $y$, por otra, funcionan a una escala que puede ser llamada local (es decir, con un pueblo principal y un territorio en el que se ubican las estancias de pastoreo o nichos agrícolas). ${ }^{6}$

por lo que las comunidades que trataré en este trabajo, al menos hasta hace algunos años, se encontraban en una posición relativamente marginal.

5 Aunque este es un problema que atañe a muchas comunidades, se presenta con particular fuerza entre las más cercanas al río Loa, afectadas por los recursos de agua que consumen los grandes proyectos mineros y ciudades como Calama y Antofagasta.

6 El patrón de pueblo-estancias ha sido descrito para la zona en Aldunate y colaboradores (1986). Básicamente, consiste en un pue- 
Ese es el caso de las comunidades de Toconce, Ayquina y Caspana, que abordaré a continuación.

Lo que muestran los relatos entregados por los comuneros, es que parecieran funcionar de manera simultánea y sin contradicciones varios tipos de registro de memoria. Algunos de esos relatos efectivamente concuerdan con lo que señalan los registros documentales, pero otros, en particular los que hacen referencia a lo que podríamos denominar las identificaciones locales, minimizan o descartan procesos comunes (como haber formado parte de una misma comunidad en tiempos coloniales), o funden en un solo proceso histórico que una mirada de especialista, separaría (como la presencia, en el s. XIX, de la república de Bolivia y posteriormente de Chile). Todo ello, sin embargo, entretejiendo además un fino diálogo con diversos conjuntos de relatos míticos conocidos para otras regiones andinas. Esto recuerda esa suerte de doble o triple condición que tenían los relatos que destacó Wachtel en aquél trabajo sobre las identidades colectivas (1992: 49) y que también ha puesto de relieve Molinié (1997). Es decir, un tipo de memoria que conserva retazos de procesos históricos ocurridos en un área, junto a un tipo de relatos que reordenan esos materiales para construir nuevos textos orales más locales teniendo, como telón de fondo, un conjunto de narraciones y rituales que remiten a otro tipo de permanencias e historicidades.

\section{Toconce}

Hace años atrás tuve la oportunidad de asistir a la fiesta con la cual se daba por finalizado el ritual de la limpia de uno de los canales de riego que alimentan los culti-

blo central (cabecera de la comunidad) resultado de un proceso de reducción colonial o de nucleamientos posteriores y un conjunto de "estancias" o pequeños nichos en los que se ubican, dispersas, las viviendas temporales de algunos comuneros. Cada comunidad mantiene sus propias estancias y, en los lugares en que hay presencia de más de una, los sitios y recursos empleados están separados. Asimismo, no todos los comuneros tienen estancias en los mismos lugares. vos de la comunidad de Toconce ${ }^{7}$ (Figura 1). ${ }^{8}$ La fiesta se realizó en una de las casas del sector oriente del poblado, en la que, según los participantes, se debían iniciar todas las fiestas de carácter comunitario. Cuando los participantes eran muchos, podían trasladarse a la casa de la comunidad, más amplia y situada en el sector central del pueblo, no sin antes haber dado inicio a las fiestas en la anterior, la casa del jach'a tata Agapito Anza, por ser la más antigua construcción de Toconce (Martínez 1985: 103-104). La expresión jach'a tata parece aludir a quienes tenían la calidad de "gran abuelo", verdaderos fundadores de la comunidad. ${ }^{9}$

Posteriores estadías me permitieron reconocer la existencia de un relato de origen, compartido en gran medida por la mayoría de sus integrantes, en especial por los adultos y más ancianos. ${ }^{10}$ Esta narración describía la fundación del pueblo y el surgimiento de la comunidad como algo "reciente" y de lo cual todos tenían un recuerdo familiar, a veces incluso personal, aun cuando se trata de un proceso que -tal como ha podido ser documentado (Martínez 1985) - se inició a mediados del s. XIX.

7 La información etnográfica que sirve de base a este artículo fue recogida entre 1984 y 1999. Agradezco a los integrantes del Grupo Toconce por haberme incorporado a sus terrenos e investigaciones de las que, entre otras, ha resultado este trabajo. Fue gracias a mis colegas que pude disfrutar y beneficiarme de la acogida en las propias casas de las distintas personas que posteriormente entrevisté. Mis entrevistas fueron semidirigidas, grabadas y anotadas en mis cuadernos de campo. En posteriores visitas pude volver a conversar con las mismas personas u otras, que me ayudaron a aclarar, corregir o ampliar el panorama discursivo. Asimismo, tuve el privilegio de acompañar a mis colegas arqueólogos en varias ceremonias y fiestas, como limpias de canales, rituales funerarios, de salud y otros.

8 Se trata de una pequeña comunidad cuyo poblado está situado a $3400 \mathrm{~m} . \mathrm{snm}$ en la cuenca del río Salado, afluente del río Loa (II región, Chile). Al momento de registrar estas observaciones contaba con 15 a 20 familias residentes habituales.

9 Esta expresión parece ser una derivación de haya: "antiguo anciano", en aymara (Bertonio 1984 [1612]: 55), aunque esta posibilidad resultaría problemática por la casi total ausencia de términos aymara en el área atacameña, mucho más influenciada por el quechua (ver Lehnert 1981-82).

${ }^{10}$ La información que presento aquí tiene varios sesgos, entre ellos el de haber excluido a los informantes jóvenes, en su mayoría residentes en la ciudad de Calama y que podrían haber mostrado mayores distancias respecto de los relatos que pude recoger. 


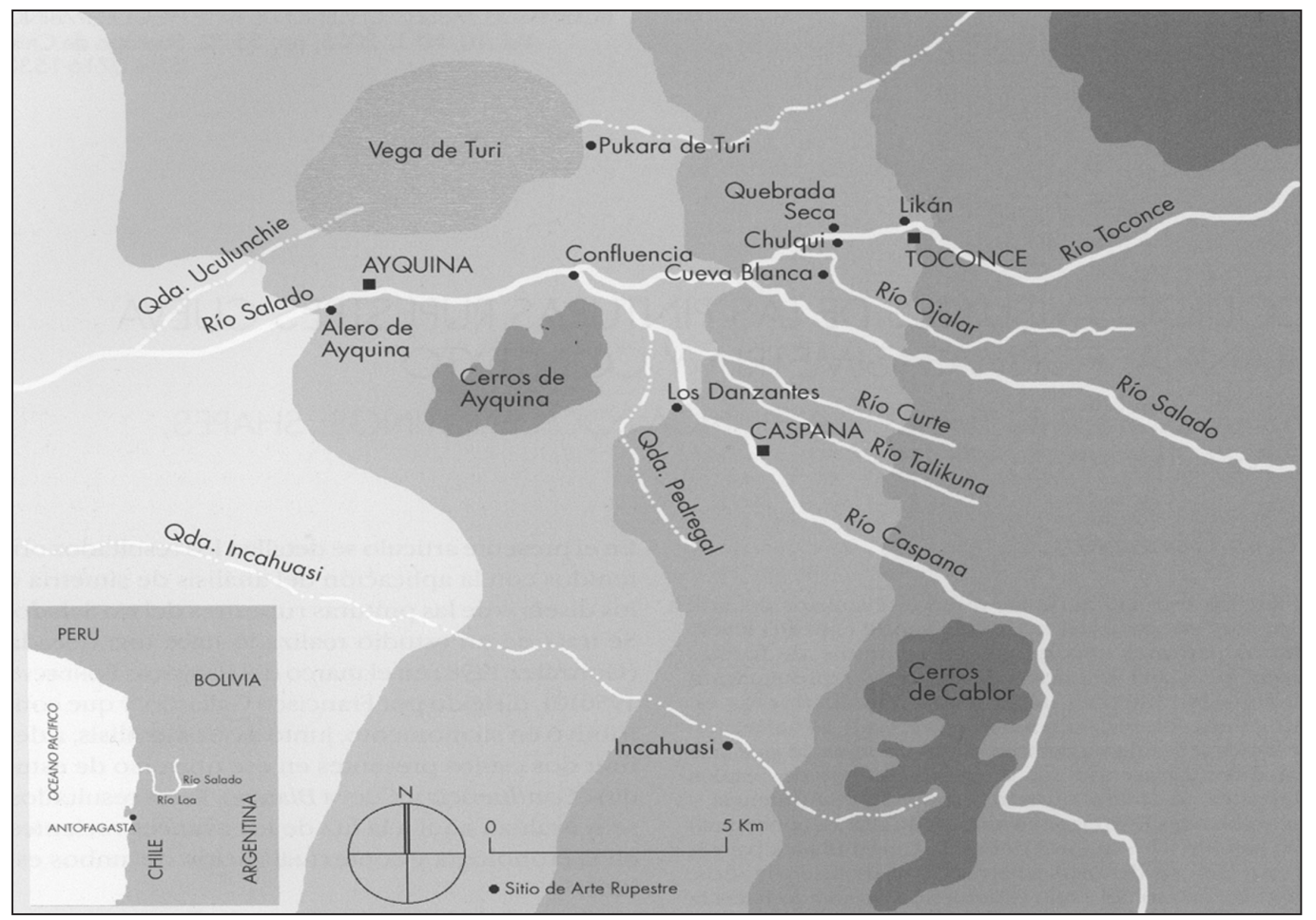

Figura 1. Comunidades de Toconce, Caspana y Ayquina, II región, Chile. Tomado de Gallardo y colaboradores (1999:58).

En esa memoria se puede identificar, por una parte, un proceso de progresivo nucleamiento del poblado, gracias a la llegada de familias procedentes de Ayquina y sobre todo de la vecina región de Lípez, en Bolivia (Martínez 1985; Aldunate et al. 1986).

"Mi abuelito cuenta que antes no era pueblo, no había este pueblecito. Dice que había unas viviendas por ahí, por alli al otro lado [...] Después empezó a llegar la gente, de estancias, como decía [...] Ya cuando él era niño ya, fueron apareciendo sus sentidos, dice que ya empezó a haber como tres casas, como cuatro casas. Así ya familias que vivían aquí, y ahí no más yo creo que empezaron a multiplicarse" (Delfina E., Toconce, 1985).

"[Mi mamita] sabe decir que habían más poco la gente. Ese otro aquí, allá, yo creo que han tenido casitas, otro por allá, por estas quebradas, por ahí encima, así tendrían casitas" (Juana C., Toconce, 1985).
En segundo lugar, el relato colectivo caracteriza ese proceso. No se trató de la llegada, puro y simple, de gente proveniente de diferentes lugares, sino que habría estado estrechamente vinculado a la rehabilitación de viejos canales de regadío prehispánicos y al empleo de una tecnología industrializada como el uso de dinamita y la ejecución de obras colectivas importantes: la construcción de nuevos caminos y nuevos edificios de piedra, como un molino."1 Todo esto asociado igualmente a un conocimiento de la tecnología occidental, al extremo que uno de los verdaderos "héroes míticos" fundadores del pueblo (Cecilio Cruz) tenía como apelativo honorífico el de "ingeniero", por sus conocimientos de hidráulica y del manejo de la piedra.

"Ahí vivía Cecilio Cruz con otro caballero. Entonces el canal era hasta por allá, a la vuelta no más y con el señor Manuel Mama-

\footnotetext{
${ }^{11}$ Ubicado en la vecina localidad de Turi, aproximadamente a $8 \mathrm{~km}$.
} 
ni, él sabía cargar tiros para tronar, porque sabía... Entonces él, con él trabajaron para allá. De ahí ya, ese fue el que hizo" (Toribio S., Toconce, 1986).

"Así era, hemos trabajado mucho ahí. Hemos empedrado el camino abierto p'al lado de Chiu Chiu, esa quebrada. Mucho hemos trabajado por ahí [...los que trabajaban eran] puro de Toconce. Los de Ayquina trabajaban pero no sabian colocar ni una piedra, ni hacer nada..." (Natividad B., Toconce, 1985).

No he podido identificar, hasta ahora, un relato único sobre esa memoria colectiva. Cada miembro de la comunidad lo cuenta a partir de su propia experiencia familiar ("mi mamita sabe decir", "mi abuelito cuenta"), lo que les proporciona un gran sentido de pertenencia y vinculación con él. No existiría, entonces, un "relato fundacional" despersonalizado, cuyos participantes se remonten a tiempos ancestrales, ${ }^{12}$ aun cuando estén presentes prácticamente todos sus elementos (héroes fundadores, lugares de origen, una espacialidad y un "viaje" desde la periferia hacia el "centro" de Toconce, una historia en común, etc.). Curiosamente, esta memoria desdeña o minimiza el rol fundacional de otros habitantes en el lugar: aquellos pastores de Ayquina de los cuales los toconcinos son igualmente descendientes (entre los cuales no se reconocen "héroes míticos" fundadores), y niega toda vinculación posible con un pasado prehispánico tan evidente como que el pueblo de Toconce está situado en medio de terrazas y andenerías de riego preincaicas y a unos cuantos cientos de metros de las ruinas de Likán, un importante poblado arqueológico preincaico (Aldunate y Castro 1981).

Las relaciones con Ayquina, una comunidad vecina, son ciertamente reconocidas. Formaron parte de una misma comunidad hasta la década de los 60 y elegían alternadamente sus "alcaldes-vara", y demás integrantes de una misma estructura religioso-política de cargos. ${ }^{13}$ Pero esa vinculación, curiosamente, parece no formar parte del relato del origen que se esfuerza, por el contrario, en enfatizar algunas diferencias: "Los de Ayquina trabajaban pero no sabían colocar ni una piedra, ni hacer nada...".

\footnotetext{
${ }^{12}$ Y que fueran descritos, por lo tanto, con categorías impersonales como las de "abuelos", "antes dice que había" u otras, tan comunes a muchos relatos míticos.

13 En la estructura de los sistemas de cargos políticoreligiosos de la región, los "alcaldes-vara" ocupan la máxima posición jerárquica.
}

\section{Ayquina}

Interesado en conocer la otra versión, la de los de Ayquina, ${ }^{14}$ me encontré con que en este lugar sí había un mito de origen, que desplazaba la fundación del poblado hacia tiempos más remotos y, por lo tanto, impersonales. ${ }^{15}$ Sus habitantes narran que antiguamente ellos no vivían en ese lugar y que ahora lo hacen por un acontecimiento divino, que sacralizó ese emplazamiento.

"En Ayquina, donde está ahora la iglesia, pues, ahí mismo eso está rellenado así, era más quebradita. Ahí que había una cortadera [Cortaderia atacamensis]. Ahí está corriendo el agüita, entonces que había unos niñitos, dos niñitos, no sé, que andaban jugando por ahí, en el agüita y después dice que han visto una muñequita que estaba ahí al lado de la cortadera y dice que dijo: oye mamita, alli hay, nos hemos encontrado una guagüita -idónde? -Ayina, por Ayquina dice que dijo el niño - Ayina he encontrado - ¿A dónde está? - Aquina dice que decía el niño. De aquí que han ido a ver, verdad dice, que estaba ahí. Ahí al lado del agüita estaba la virgencita así, bonita es que era. Después dice que sacaron de ahí, le hicieron un oratorio arriba, en la punta. Que llevaron pa'llá y cuando fueron a ver, no había ná, se había perdido. -¿y qué se haría? - diciendo. Han ido a ver ahí, donde apareció, ahí mismo dice que estaba, de nuevo estaba ahí. Entonces ellos dijeron, pensaban que era pa' Paniri; le han llevado a Paniri. Ese es un oratorio también ahí y allá le dejaron ¿Quién sería en esos años? Entonces que han llevado, que han ido a dejar allá a Paniri. Dejaron, dice que estaban viniendo por el camino, de allá, montado en animales que venían, más una tropa. Ya venían por aquí en la pampa y vieron clarito que pasaba una palomita blanca así, como que pasa pa' Ayquina. De ahí que dicen ¿qué será ese blanquito? Estaban pensando. Que han llegado en Ayquina, entonces dice que ahí mismo estaba otra vez. Ahí donde estaba al lado del agua. Y han ido a ver pa' Paniri.

\footnotetext{
${ }^{14}$ La comunidad de Ayquina tiene dos asentamientos importantes (el poblado de Ayquina y las vegas de Turi), además de otros lugares menores. Está ubicada a $3000 \mathrm{~m}$.snm en la misma cuenca del río Salado y, al momento de recolectar la información allí vivían aproximadamente entre 20 a 30 familias.

15 Soy consciente del debate actual sobre los problemas de la noción de "mito" (Calame 1990), pero su empleo es familiar a los estudios sobre las sociedades andinas y lo uso en el contexto en que lo utiliza esa tradición disciplinaria: la de un relato oral que no tiene pretensiones de una historicidad demostrable y que se opone, por eso, a otras narrativas construidas con la pretensión de ser verdades históricas.
} 
Que no estaba. Por eso dice que han rellenado ese [lugar] y han hecho un oratorio ahí mismo [en el lugar de la iglesia actual]. Ahíle pusierony de ahí no se ha movido nunca" (Gerónima B., Turi, Ayquina, 1988).

Las lecturas que es posible hacer de este mito son muchas. Únicamente quiero llamar la atención sobre algunas de las oposiciones y conjunciones en las que se insertan los personajes y lugares que operan en el mito. Aparentemente, esta narración daría cuenta del "origen" de la iglesia y consecuentemente, del poblado (que está aglutinado en torno a ella). Dos lugares son puestos en oposición: Paniri, poblado prehispánico y Ayquina, de origen colonial. Así también entran en oposición los lugares religiosos de altura (la "punta" adonde es llevada inicialmente la virgen, ilos cerros?), muy andinos, contra los santuarios en lugares bajos (la "quebradita" donde aparece y permanece), de mayor identificación hispana y que termina por vencer a los cerros. ${ }^{16}$

Las descripciones que se hacen de la virgen parecieran estar en esa misma línea de lectura. La imagen inicial, "chiquitita", como "guagüita" o "muñequita", que oculta su calidad a los ojos de los lugareños y que recuerda mucho el tema de las representaciones "miniaturizadas" de las divinidades andinas (Cobo 1964: 166-67; Cereceda 1988) así como el de las iyas, contrasta con la paloma blanca, inequívoco símbolo cristiano y el reconocimiento final de su calidad sagrada.

La descripción de esos antepasados resulta igualmente sugerente. No solo eran incapaces de reconocer a la virgen cristiana (la palomita blanca: "iqué será ese blanquito?"), ${ }^{17}$ sino que incluso, los niños no podían hablar bien ("Ayina, por Ayquina dice que dijo el niño

\footnotetext{
${ }^{16}$ Este tipo de espacialidades diferenciadas entre lo alto/cerros y lo bajo/valles, quebradas, ha sido destacado para otros lugares de los Andes, puesto que la colonización española se esforzó por "bajar" a las poblaciones de los cerros y concentrarlas en lugares que, para el pensamiento español, parecían más accesibles como los valles o lugares bajos (F. Pease com. pers. 1982). Este es un tipo de oposiciones conceptuales que puede encontrarse en muchos documentos del s. XVI (Martínez 2009).

${ }^{17}$ La dificultad, de alguien o de algo, de ser reconocido, inicialmente, por otros como lo que realmente es, parece ser otra de las características de las manifestaciones sagradas andinas (V. Cereceda, com. pers., 2005).
}

-"Ayina he encontrado" - “iA dónde está?" - "Aquina dice que decía el niño."). Se trata de un error reiterado: Ayina, Aquina, aun cuando el interlocutor del relato sabe correctamente que se refieren a Ayquina. Más que dar cuenta de una enunciación posicional ("alli", "ayi-na" "aqui", Aquí-na) lo que el relato (y la narradora posteriormente) enfatiza es una característica comunicacional que hace que la interlocución sea dificultosa. ¿Se trataba acaso, de una humanidad "disminuida", sin las capacidades de la actual? Esta posibilidad tiene una reminiscencia con los mitos aymara del Altiplano Central, respecto de la existencia de humanidades anteriores, caracterizadas por ser incapaces de diferenciar bien y de reconocer los objetos, principalmente porque en ese tiempo anterior no existía una luz solar que permitiera distinguir agudamente con la mirada. ${ }^{18}$ Se trata, sin embargo, de una versión completamente recontextualizada, aplicada ya no a diferentes edades del mundo andino prehispánico, sino a distintos tiempos de un mundo que incorpora lo cristiano (colonial) como una nueva edad.

Todos estos elementos confluyen para mostrar cómo el relato de origen de Ayquina pareciera ubicar a la localidad en una transición, ya histórica, entre un poblado prehispánico (Paniri) y otro, nuevo y de origen colonial, asociado probablemente a los procesos de evangelización y de reducción de los s. XVI y XVII (de allí el énfasis en la iglesia y no en el poblado, que aparece como consecuencia). ${ }^{19}$

Hay otro elemento que refuerza esta caracterización. Las actuales autoridades de Ayquina usan unas varas similares a bastones que son llamadas "varas de rey Inka". ${ }^{\circ}$ Aunque las varas, como emblema de las autoridades

\footnotetext{
${ }^{18}$ Wachtel (1974, 1978 y 1990), ha trabajado extensamente este mito. Cereceda (1990: 72 y ss.) ha analizado el tema de la percepción "disminuida" de los chullpa.

19 No se puede olvidar aquí la importancia tanto del proceso evangelizador, que se inició en la zona con la pacificación a partir de 1557, como de los varios procesos de extirpación de idolatrías que se realizaron durante el s. XVII entre las mismas comunidades que trata este trabajo. Ver Castro (1997).

${ }^{20}$ También en Calcha, en la región de Chichas al sureste de Bolivia, las varas ceremoniales son denominadas como "varas de rey Inka" (R. Martínez com. pers. 2006). Me parece interesante que se trate de otra región y una localidad con la cual los habitantes de Atacama mantuvieron fuertes contactos, algunos de los cuales se conservan hasta hoy.
} 
comunales, fueron impuestas por los españoles, éstas en particular muestran nuevamente la ambigüedad o la transición, puesto que no son reconocidas como hispanas sino como del "rey Inka". Ese es el mismo nombre que se da en las narraciones locales a la divinidad cultural y ordenadora que, con el auxilio de su vara, movía cerros, hablaba con las piedras, ordenaba el paisaje, todo ello antes de la invasión europea, por supuesto.

“...como eran poderoso los rey Inka; ellos conversaban con viento $y$ con aire, con agua, con nube, con todo conversaba [...] Pero ellos hablaban con las piedras poh. Usted decía bueno piedra, ayúdame, bueno, date vuelta piedra, la piedra poquito le daba vueltas y la piedra sola se tumbaba. Le asentaban por ahi, hacían las murallas, en Turi usted ha visto, unas piedras grandes están puestas. Ellos hablaban..." (Juan A., Toconce, 1985).

El emblema colonial tiene, por esta vía, una caracterización similar a la del poblado y de sus habitantes: herederos de una transición y de una tensión entre un pasado prehispánico y un tiempo colonial, ya histórico.

En este contexto, no debe extrañar que muchos de los ayquineños sí reclamen algún tipo de vinculación o de propiedad con las ruinas arqueológicas ubicadas en las inmediaciones, en especial con Turi, enorme poblado que después albergó a un centro administrativo incaico, ubicado a no más de $5 \mathrm{~km}$ de distancia, y con Paniri, el lugar de poblamiento inicial mencionado en el relato, que son usados hasta hoy como lugares de residencia, pastoreo y agricultura. Un detalle, sin embargo, llama la atención. El lugar prehispánico mencionado es Paniri y no Turi, la gran ciudad, situada mucho más cerca de Ayquina que Paniri y donde las investigaciones arqueológicas han evidenciado una importante ocupación no solo incaica sino también colonial (Aldunate 1991). Si se tuviera que hacer alguna afirmación desde la arqueología y la etnohistoria, se podría decir que Turi representó un elemento importante de continuidad entre el período Incaico y el Colonial y que habría sido desde allí que se desplazó a la población para fundar Ayquina, con su propia iglesia y cementerio. Pero sobre eso los narradores hacen un silencio.

Lo otro que este relato no menciona, es la antigua relación que, a su vez, tenía la comunidad de Ayquina con la de Caspana, ubicada igualmente en las inmediaciones, a no más de $15 \mathrm{~km}$ de camino. ${ }^{21}$ En la geografía local de ambas comunidades abundan los sitios preincaicos e incaicos. ${ }^{22} \mathrm{Y}$ existen antecedentes documentales coloniales que señalan que en diferentes momentos de los s. XVII y XVIII ellas conformaron una misma unidad sociopolítica, compartiendo autoridades, tal como años más tarde, ocurriría entre Toconce y Ayquina (Aldunate et al. 1986; Martínez 1998). Pero el relato de origen es explícito en referirse únicamente al desplazamiento desde Paniri hacia Ayquina y no menciona a Caspana ni a otros sitios ubicados en sus proximidades.

Más aún. En Ayquina no hay recuerdo de esa estrecha relación comunitaria y, para los ayquineños, los habitantes de Caspana representan claramente "un otro", diferente a ellos. Mientras los habitantes de Ayquina y Toconce hablaban quechua hasta hace poco tiempo atrás, los de Ayquina señalan que los caspaneños hablaban otra lengua, diferente. Esas diferencias lingüísticas fueron probablemente originadas por el arribo masivo, a partir de la segunda mitad del s. XIX, de gente quechua-hablante venida de la vecina región de Lípez (Bolivia). Así, mientras Caspana (con baja afluencia de forasteros) siguió hablando kunza hasta hace unas décadas atrás; en Ayquina y Toconce (y especialmente en esta última), se impuso el quechua. Lo que se destaca en los relatos de Ayquina, sin embargo, no es el proceso de diferenciación, sino la constatación de esa diferencia. Junto con hablar otra lengua, los de Caspana, nos señalaron, tenían otra música, no la de las arpas de cajón y las guitarras empleadas por los ayquineños y toconcinos en sus rituales de la limpia de canales (Castro y Varela 1994; Mercado et al. 1997).

\section{Caspana}

La respuesta de los caspaneños ante la cuestión de cuál era su propio origen y de si habían tenido alguna relación con Ayquina o Toconce fue, para mí, sorprendente. Conversando con algunos de los más ancianos de la localidad, ellos se autodescribieron, con una importante

\footnotetext{
${ }^{21}$ La comunidad de Caspana, situada a 3300 m.snm. está situada a orillas del río Caspana, afluente del río Salado, en la misma cuenca que las otras dos comunidades aludidas. Se trata de la mayor de las tres. En la década de los 90 tenía aproximadamente 35 a 40 familias.

${ }^{22}$ En la Figura 1, se han marcado varios sitios con arte rupestre tales como Los Danzantes, Confluencia y Cueva Blanca, entre otros.
} 
cuota de orgullo, como "resto de gentiles". ${ }^{23}$ Es decir, su origen se remontaría a tiempos claramente prehispánicos, en el extremo opuesto, si se quiere, de la "contemporaneidad" moderna de Toconce y también anteriores a los actuales habitantes de Ayquina. Aunque sin una enunciación explícita, por primera vez tenía ante mí el despliegue de un meta relato que hacía dialogar, a través del posicionamiento en el espacio simbólico de diferentes tiempos y edades, a las tres comunidades. Según los habitantes de Caspana, Toconce es un pueblo de allegados, es muy nuevo, y Ayquina, aunque es más vieja, no lo es tanto. "¿No ve que recién apareció ahí la Virgen? Antes vivían en Paniri. Caspana es el pueblo más antiguo" (Julián C., (†) Caspana, 1991).

Restos de gentiles, chullpa puchu como se designa en el altiplano aymara a los uros y a otros grupos que también hacen válida esa adscripción para construir sus identidades (Wachtel 1990: 569). La versión local de Caspana, sin embargo, tiene una interesante variación respecto del relato canónico. En las versiones aymara más conocidas, los chullpa murieron por la salida del sol, que trajo consigo también a una nueva humanidad, la aymara, en un tiempo que es siempre ubicado mucho antes de la invasión europea a los Andes (BouysseCassagne y Harris 1987: 19 y ss.; Wachtel 1990: 13). En el relato caspaneño, en cambio, aunque se conoce y cuenta esa primera versión, ${ }^{24}$ hay otra más local. Al comentar a algunos viejos pobladores que en Toconce me habían relatado que los "gentiles" murieron porque el Sol se acercó mucho y se quemaron, la respues-

\footnotetext{
${ }^{23}$ El término "gentiles" de clara raigambre cristiana, evoca un momento de ruptura, el de la evangelización. Genéricamente, "gentiles" designa a todas las poblaciones anteriores al advenimiento de Cristo y que, por lo tanto, no tuvieron una ignorancia culpable puesto que carecieron de la posibilidad de ser bautizados. En los Andes el término tiene también una connotación temporal: define por extensión a los habitantes de cualquier sociedad o humanidad considerada anterior a la invasión europea, es decir, gente de edades anteriores (Wachtel 1978, 1990) y en algunos lugares están revestidos de ciertas capacidades mágicas o comunicativas con las divinidades.

${ }^{24}$ No se trata solo de una versión conocida, sino en parte, también vivida. Mencionando la luz lunar que alumbraba a los "gentiles" en los relatos altiplánicos, una caspaneña me insistía que en Caspana, también, "hasta hace pocos años atrás la Luna era mucho más clara" (Catalina T., Caspana 1991). Es decir, no se trataría de una condición ajena a los actuales habitantes de la localidad.
}

ta caspaneña fue: "Así dicen algunos. Otros dicen que fue porque salió el Sol". Más adelante, sin embargo, me agregaron: "También [cuentan] que llegaron los españoles y los empezaron a bautizar, entonces ellos se fueron muy lejos y con la pena murieron" (Caspana 1990). El relato oral en Caspana, entonces, es que los "gentiles" murieron de pena por la invasión europea y por ser bautizados.

Sin mencionarlo, los textos orales de Ayquina y Caspana se relacionan, tomando posiciones respecto de la ruptura colonial. Aunque ninguna de las dos comunidades guarde una memoria manifiesta acerca de su origen común, esos textos orales los aproximan puesto que mientras los ayquineños actuales descienden de los bautizados, de los que aceptaron el cristianismo y provocaron una ruptura con su pasado, los caspaneños son "restos" de la otra posición, la del rechazo. Desde esa condición de "gentiles", algunos ancianos de Caspana expresaron que "los bolivianos y los de Toconce, son distintos", diferenciándose de los caspaneños y ayquineños que serían restos de las "antigüedades", una condición que el relato de origen de Ayquina se empeña en negar.

El pueblo de Caspana, entonces, no tiene un relato acerca de una fundación que pueda ser datada históricamente, como los de Ayquina y Toconce, sino que por el contrario, lo que se enfatiza es la continuidad. El pueblo mismo se encuentra emplazado a un costado de un antiguo cementerio prehispánico y del período Colonial Inicial (Barón 1979; Uribe 1997; Manríquez 1999-2000.). Hay una cierta convivencia con los restos arqueológicos del lugar. Un ejemplo de ello son las tumbas construidas con muros de piedra con una estrecha abertura, que cierran pequeños salientes de las paredes de la quebrada en la que se ubica Caspana, algunas de ellas situadas a escasos metros de las casas. Esas tumbas prehispánicas son llamadas localmente trojas o trojes (depósitos), y aunque varias tuvieron restos arqueológicos hasta hace pocas décadas atrás, ahora son usadas como depósitos para los granos y semillas, o para conservar frescos algunos alimentos. Lo interesante es la convivencia y la utilización continua de esos recintos, lo que en Toconce sería impensable (puesto que han cortado su vínculo con esas ruinas) y en Ayquina las actuales viviendas se ubican a un costado de algunos sitios tales como Turi o Paniri, 
pero no dentro de ellos y, menos, utilizándolos como parte de una actividad cotidiana. ${ }^{25}$

Es cierto que esta condición de "gentilidad" no es fácil. Conlleva diversos riesgos. De allí, tal vez, la abundancia de cruces puestas en diversos lugares, rodeando al pueblo y "protegiéndolo", tal como lo indicaron sus propios habitantes. ${ }^{26} \mathrm{Y}$ de ahí también una cierta incomodidad conceptual y terminológica, porque en el sistema local de las comunidades del río Loa, "gentiles", "abuelos", o "antiguos" son términos que pueden confundirse y confundirlos, con una cierta carga peligrosa. Una vez, me relataron que, un chiquito aprendiendo a hablar le dijo "abuelito" a una persona mayor. "iQue me dices abuelo! No soy abuelo, si fuera abuelo estaría en las trojas", fue la reacción inmediata (Catalina T., Caspana 1991).

En distintas conversaciones se hace uso del término "antiguos", así como de "abuelos" y "gentiles". Todos ellos para referirse a una humanidad que no es la actual, pero en la cual parecen entrar todos los antepasados desde la cuarta generación para atrás hasta los tiempos de rey Inka. "Gentiles" es más preciso para la gente prehispánica. En tanto que "abuelos" y "antiguos" envuelven una gran ambigüedad semántica. Curiosamente, son éstos los términos más empleados. En un esfuerzo por introducir mayor precisión, un caspaneño se refería a los "tatarabuelos" y "mamarabuelas" como sinónimo de antiguos (él mismo era bisabuelo, lo que le dificultaba aún más las cosas). "Antiguos" se usa para referirse a todo aquello sobre lo cual ya no se guarda una memoria oral. Es también un término genérico para evadir preguntas. "Es de los antiguos" implica necesariamente un desconocimiento $y$, por tanto, la ausencia de una explicación. Pero los "antiguos" pueden ser los propios antepasados y, los "abuelos" ya no consanguíneamente sino cronológicamente. La comunidad de Caspana, en el s. XIX, por ejemplo, también corresponde a "los antiguos", condición que - sin embargo- no se presenta en Toconce, donde los jach'a tata no podrían ser pensados como "abuelos" o gentiles. ${ }^{27}$

\footnotetext{
${ }^{25}$ Excluyo los corrales, muchas veces construidos con piedras obtenidas de los recintos prehispánicos, puesto que ellos no son reutilizaciones, sino nuevas construcciones.

${ }^{26}$ Lo que podría ser interpretado como una cierta ambigüedad, dado que las cruces, coloniales y cristianas, evocan precisamente el fin de los antiguos. Ver Molinié (1997).

${ }^{27}$ Los problemas que esto plantea como categorías clasificatorias
}

\section{* Representando el tiempo}

Los planos de este sutil diálogo temporal entre las tres comunidades parecieran ser varios. Uno de ellos es el de los rituales y la música. Ya se ha demostrado cómo, entre los jalq'a y Tarabuco en los alrededores de la ciudad de Sucre, en Bolivia, la música ha sido utilizada para construir calendarios anuales (R. Martínez 1994, 1996a). Pero, ¿cómo se pueden significar unidades mayores de tiempo, como las edades de los gentiles, del rey Inka o de la cristiandad? Algo de esto aparece en el sistema de rituales de limpia de canales de las tres comunidades mencionadas. Señalé inicialmente que en la "limpia de canales" de Toconce, el instrumento más usado era un arpa de cajón, a la que hay que agregar las trompas de cuernos, que son llamados "clarín". El instrumento de cuerdas está claramente adscrito a un origen europeo, no así el de viento. No es evidente, por cierto, que las arpas sean por su sola condición percibidas o valoradas como europeas o posthispánicas por sus ejecutantes; sin embargo otros trabajos han mostrado que en diversas comunidades andinas, las arpas a menudo son valoradas como instrumentos asociados a un culto litúrgico católico (de origen colonial) y son consideradas como instrumentos que vienen del mundo exterior (R. Martínez 1996b).

El caso de los "clarines" merece igualmente una atención. Estos instrumentos son conocidos también como pututu en quechua, por lo que me parece que el nombre "clarín" intenta ubicarlos igualmente en ese contexto cultural y temporal ocupado simbólicamente por las arpas: se trataría de instrumentos valorados como posthispánicos. Una nota de cautela es necesaria aquí, porque no se puede negar la situación ambigua del "clarín", que mezcla lo antiguo de su origen y uso con la modernidad del nombre. Se trata de una condición que parece repetirse con las letras de las canciones que se cantan en ese ritual, las que están alternativamente en castellano y quechua y serían, por ello, isomórficas con los instrumentos: arpa y

u ordenadoras son muy sugerentes. "Gentiles", por otra parte, es una categoría que se opone a la de persona. Mientras los ayquineños y toconcinos se autodefinen como personas, señalan que los de Caspana no lo son, puesto que son (o tienen mucho de) "gentiles". Una mujer de Ayquina explicaba que allí las trojas habían sido construidas hace poco, por abuelos; aclarando de inmediato: "son hechas por persona". En cambió, agregó, "los gentiles no son persona". 
pututu (una "externa" o colonial, el otro "local" pero ubicado en un contexto externo a lo colonial) y con el pututu mismo, que con su nombre de "clarín" reitera la pareja simbólica de lo local con una connotación no local. ¿Esta situación podría leerse como una metáfora de la propia condición de los toconcinos que reconocen en el plano del ritual y la música una situación de ambigüedad que sus relatos orales niegan?

En Ayquina ocurre algo muy similar respecto de la relación entre lo colonial y lo prehispánico, pero con un matiz: lo hispano aparece aún más acentuado, puesto que al arpa se agregan las guitarras y se canta una canción titulada "el alabado", en castellano. Me parece sugerente el aparente énfasis religioso que evoca el nombre de la canción.

En Caspana, por el contrario, todo está orientado a reposicionar un mundo no hispanizado. La limpia de canales es una fiesta que se hace "desde que comenzó Caspana, desde los abuelos" (Julián C.,(†) Caspana, 1991). Antes se tenía más respeto y quien no lo hacía bien, la tierra lo castigaba, enfermándolo, y había que hacer "pagos" para lograr la sanación. Es un momento peligroso, pues la tierra está abierta. La canción principal es el kausulor, antigua canción en la extinta lengua kunza atacameña cuya letra probablemente pocos o nadie son capaces de entender. Lo importante es que ella es en "lengua" y no en castellano, como me lo reiteró un caspaneño. Los instrumentos son aquí de viento y percusión (una configuración prehispánica), ${ }^{28}$ y algunos también poseían nombres propios en kunza, como los zolbar, un par de pequeños tamborcillos de valoraciones masculina y femenina. Finalmente, conviene recordar que el baile de la limpia, es llamado "de los abuelos".

Pareciera, entonces, que hay una concentración de significantes orientados a ratificar, también en algunos rituales, las posiciones temporales narradas en los relatos orales y en la memoria colectiva.

\section{* Elementos para una Reflexión}

¿Qué tenemos hasta aquí? Desde la perspectiva de la arqueología y de la etnohistoria, lo que resalta es que las tres comunidades comparten un pasado prehispánico, en el cual se pueden observar muchas relaciones

\footnotetext{
${ }^{28}$ Agradezco a Rosalía Martínez esta información (com. pers., 2006).
}

y momentos culturales comunes. Igualmente, al menos Ayquina y Caspana compartieron un pasado colonial y fueron una misma comunidad. A su vez, Ayquina y Toconce, que fue una estancia de pastoreo de Ayquina durante el período Colonial, fueron una misma comunidad durante el s. XIX y mediados del XX, cuando el crecimiento de Toconce le permitió separarse y constituir una unidad política y social autónoma.

Las tres comunidades compartieron también, hasta tiempos relativamente cercanos (los años 50 y 60), tanto un conjunto de prácticas productivas (con énfasis en la agricultura y en la ganadería aunque con posibles matices de diferenciación en las actividades de caza y recolección), como similares estructuras sociopolíticas (sistema de cargos político-religiosos anuales). Las diferencias lingüísticas, menores en la actualidad, en que todos hablan castellano y únicamente algunos ancianos conservan algo de quechua (y nadie, kunza, hablado coloquialmente), parecen ser mucho más recientes que la larga historia compartida que se percibe desde la arqueología o la etnohistoria, y ciertamente pertenecen a un momento anterior al de los enunciantes de estos relatos.

Por otra parte, son varios los trabajos etnográficos que han dado cuenta de la estrecha relación religiosa existente hasta la actualidad entre las tres comunidades. Todas ellas han compartido las "visitas" de las santas y santos patronos, realizada con ocasión de las fiestas patronales de cada una (Castro y Martínez 1996). Y las relaciones de parentesco son también bastante fuertes, puesto que es frecuente la existencia de matrimonios entre miembros de una y otra comunidad, así como también varios de ellos residen en los poblados de las otras comunidades. En definitiva, desde una cierta mirada, podría fácilmente enfatizarse la integración y los elementos compartidos o comunes.

Lo que me parece llamativo, es que en esos relatos sobre los orígenes de los poblados de las tres comunidades no se dé cuenta de esos procesos, sino de las lecturas culturales que cada una de ellas ha hecho sobre sí misma y sobre las otras y de sus propias lecturas de los discursos dominantes, de las apropiaciones que esas comunidades hicieron ya fuera de los discursos y prácticas evangelizadoras coloniales como de los discursos modernizantes de los estados nacionales. Se trata de relatos que enfatizan ciertas diferencias y construyen nuevas distincio- 
nes, casi como elaborando una posición alternativa, que permita matizar al menos intelectualmente la estrecha relación cultural existente en la práctica.

Este diferente posicionamiento tiene una posible lectura que me parece sugerente a la hora de entender estos procesos de producción simbólica. Los antecedentes históricos de las tres comunidades no son los mismos si se los observa desde el punto de vista de su emergencia como comunidades independientes. No puedo dejar de plantearme la posibilidad de que la relación "gentiles-evangelizados" que distingue a caspaneños y ayquineños haya forzado a los toconcinos hacia un discurso de modernidad, tanto porque esas otras posiciones identitarias y discursivas ya estaban "ocupadas", como porque Toconce, la más nueva de las tres, vivió también más intensamente el proceso de delimitación fronteriza y, por lo tanto, tuvo aparentemente una mayor presión de parte del Estado chileno.

Lo segundo que quiero destacar es que la materia básica para construir esas diferenciaciones, para darle coherencia al conjunto y volverlo significante de las diferentes posiciones locales, es el tiempo. En efecto, lo que me parece más significativo es el distinto posicionamiento temporal de cada una de las comunidades. A partir de allí surgen las diferencias.

Estos relatos se basan en un conjunto, reutilizado y reordenado, de varios ciclos míticos que tienen una dispersión mayor en los Andes. Aparecen aquí, el relato de las edades del mundo, en su versión altiplánica (tiempo sin luz, de chullpa / tiempo de luz-Sol, de hombres); el ciclo mítico de rey Inka o Inkarrí; la captura y muerte de Atahualpa; el ciclo de las vírgenes y santos coloniales que "llegan" (Pease 1977; Vilcapoma 2006: 50; V. Cereceda com. pers., 2006); y, finalmente, una lectura muy local acerca de la "modernidad" y la tecnología. Todos esos ciclos comparten un elemento: son reflexiones que se ubican en el tiempo, todos permiten marcar diferentes tipos de un "antes" y un "después". Se trata de usar el tiempo como material para producir clasificaciones identitarias.

Quisiera llamar la atención, también, sobre lo que podríamos llamar la "lectura" local que se hace sobre determinados acontecimientos. Los hitos "históricos" que aparecen puestos en juego son, básicamente un tiempo entendido como anterior a la invasión española, el tiempo del Inka y un tiempo post invasión, el colonial, que aparece subjetivado sobre todo en sus aspectos religiosos de la evangelización y -tal vez- de la extirpación de idolatrías. El tiempo republicano, que en la zona tuvo primero la presencia de Bolivia y posteriormente de Chile, aparece más sutilmente esbozado. Los de Toconce "son bolivianos", pero no se enfatiza que los de Caspana o Ayquina sean chilenos, sino "anteriores". Y ser boliviano aparece sobre todo como parte de una modernidad, de un tiempo más actual, en el que la presencia histórica de ambas naciones no pareciera ser relevante. No al menos en esta narrativa.

Esto no deja de ser sugerente, porque en otros relatos locales sí aparece el trauma de la "chilenización" forzada a la que fueron obligados los habitantes que decidieron permanecer en sus comunidades y no "regresar" o ser desplazados a Bolivia, a fines del s. XIX e inicios del XX, cuando se enfatizó la presencia del Estado chileno en la región (Martínez 1994). Y la presencia de los Estados nacionales, en especial el chileno, ha sido uno de los elementos en los que han puesto en relieve diversos estudiosos para el análisis de la construcción de las identidades andinas más contemporáneas, en particular en el norte de Chile (Gunderman et al. 2003). Sin embargo, en esta narrativa esa presencia y ese proceso están, si no ausentes, muy desdibujados. ¿Se trata de una elección consciente, que descartó ciertos procesos considerados poco relevantes en la emergencia de diferenciaciones e identidades locales o estamos frente a un tipo de mecanismo cultural que necesita un período para "decantar" para que los actores locales (puedan rescatarlo o enfatizarlo para ser incorporado a esa narrativa de diferencias e identidades?

Finalmente, tengo la sospecha, por lo que he podido observar y conversar con comuneros más jóvenes en estos últimos años, que se trata de un tipo de construcciones "frágiles" o sometidas a diferentes tensiones, en parte por el dinamismo de las actuales construcciones identitarias. Las presiones contemporáneas por participar en procesos de etnogénesis y autoetnificación, por una parte, y la difusión de un saber académico, ${ }^{29}$ por otra,

\footnotetext{
${ }^{29}$ En el caso de estas tres comunidades, esto es muy importante. Desde hace más de 20 años que trabajan en la zona equipos de arqueólogos y antropólogos que como parte de sus compromisos éticos, han entregado a las comunidades sus publicaciones o los
} 
pueden estar haciendo mucho por cambiar radicalmente este meta relato que he descrito.

Existe otro aspecto que confluye para hacer de este tipo de relatos unas narrativas sometidas a diferentes tensiones. Me refiero al impacto ideológico que están alcanzando las narrativas "historicistas" entre los intelectuales y dirigentes indígenas, en el sentido de desarrollar una construcción lineal que pretende ser verdadera y única, que aparecen como formas legitimadas de reclamar una antigüedad y una identidad y, por esa vía, obtener un reconocimiento particularmente de parte del Estado y las sociedades dominantes. Como puede advertirse a partir de lo que he presentado, la alternativa "no historicista" da pie a la conformación de varias narrativas, de distintas historias, en las cuales ni la linealidad, ni la veracidad ni menos la unicidad son principios organizadores.

\footnotetext{
han invitado a participar de algunos de los seminarios realizados en las mismas comunidades. Más recientemente, la Escuela Andina, un proyecto llevadó a cabo por la Universidad Católica del Norte, con sede en San Pedro de Atacama, ha tenido gran importancia en la difusión de ese saber académico entre los dirigentes atacameños. Finalmente, no puedo dejar de mencionar en este proceso, la incidencia de las lecturas de los dirigentes étnicos y de los intelectuales indígenas sobre ese saber académico, como parte de sus luchas por el reconocimiento.
}

Pero la idea de la "fragilidad" va más allá. Lo que sugiero es que se trata de materiales optativos, a disposición de las comunidades que pueden, estratégicamente y de acuerdo a los procesos de unidad o diferenciación (al menos) poner de relieve determinados énfasis, acentuar posicionamientos, o reordenar por completo esas narrativas. El tiempo es, en definitiva, un material usado para significar. Lo descrito aquí, por lo tanto, sería un "momento" narrativo, dentro de, o junto a, varios otros. Es muy probable que, antes de iniciarse la etapa más reciente del proceso de poblamiento por parte de las poblaciones de Lípez hacia las de este sector atacameño, se hubiera podido encontrar otros relatos y me parece claro que lo que hoy está ocurriendo es la génesis de un nuevo "momento".

Agradecimientos En primer lugar, a todas aquellas personas que me acogieron en sus casas en Toconce, Ayquina (Turi) y Caspana, a las y los comuneros que me dieron su tiempo para contarme sus propias historias y soportar mis asedios. A los amigos y colegas arqueólogos del Grupo Toconce sin los cuales no hubiera llegado hasta esas comunidades y a mis colegas y amigas Viviana Manríquez y Cecilia Sanhueza, que me acompañaron en ese tiempo de recolección de datos, de caminary de pensar estos temas.

\section{$*$ Referencias citadas}

ALDUNATE, C., 1991. El pukara de Turi: Un testimonio monumental de continuidad cultural en la subárea Circumpuneña (s. XI al XVII). Actas del XII Congreso Nacional de Arqueología Chilena, vol. 2, pp. 61-78. Temuco.

ALDUNATE, C. y V. CASTRO, 1981. Las chullpa de Toconce y su relación con el poblamiento altiplánico en el Loa Superior, período Tardío. Ediciones Kultrún, Santiago.

ALDUNATE, C., J. BERENGUER, V. CASTRO, L. CORNEJO, J. L. MARTÍNEZ y C. SINCLAIRE, 1986. Cronología y asentamiento en la región del Loa Superior. Universidad de Chile, Santiago.

BARÓN, A. M., 1979. Un cementerio de contacto español-indígena. Actas del VIII Congreso de Arqueología Chilena. Editorial Kultrún, Santiago.
BERTONIO, L., 1984 [1612]. Vocabulario de la lengua aymara. Edición facsimilar, CERES-Instituto Francés de Estudios Andinos, MUSEF, La Paz.

BOUYSSE-CASSAGNE, T. y O. HARRIS, 1987. Pacha: En torno al pensamiento aymara. En Tres reflexiones sobre el pensamiento andino. J. Medina (Ed.), pp. 11-6o. HISBOL, La Paz.

CAJÍAS, F., 1975. La provincia de Atacama 1825-1842. Editorial Universo, La Paz.

CALAME, C., 1990. Illusions de la mythologie. Nouveaux Actes Sémiotiques 12: 5-35.

CASTRO, V., 1997. Huacca mucchay. Evangelización y religión andina en Charcas, Atacama la Baja. Tesis de Magíster en Historia, 
mención Etnohistoria, Departamento de Ciencias Históricas, Universidad de Chile, Santiago.

CASTRO, V., C.ALDUNATE y J. BERENGUER, 1984. Orígenes altiplánicos de la fase Toconce. Estudios Atacameños 7: 209-235.

CASTRO, V. y J. L. MARTÍNEZ, 1996. Poblaciones indígenas de Atacama. En Culturas de Chile. Etnografia, sociedades indigenas contemporáneas y su ideología, J. Hidalgo, V. Schiappacasse, H. Niemayer, C. Aldunate y P. Mege (Eds.), pp. 69-109. Editorial Andrés Bello, Santiago.

CASTRO, V. y V. VARELA (Eds.), 1994. Ceremonias de tierra y agua. Ritos milenarios andinos. FONDART, Santiago.

CERECEDA, V., 1988. Aproximaciones a una estética andina: De la belleza al tinku. En Raíces de América: El mundo aymara, X. Albó (Comp.), pp. 283-364. Alianza Editorial, Madrid.

1990. A partir de los colores de un pájaro... Boletín del Museo Chileno de Arte Precolombino 4: 57-104.

COBO, B., 1964 [1653]. Historia del Nuevo Mundo. Biblioteca de Autores Españoles, vol. 91-92. Ediciones Atlas, Madrid.

GALLARDO, F., C. SINCLAIRE y C. SILVA, 1999. Arte rupestre, emplazamiento y paisaje en la cordillera del desierto de Atacama. En Arte rupestre en los Andes de Capricornio, J. Berenguer y F. Gallardo (Eds.), pp. 57-96. Museo Chileno de Arte Precolombino, Santiago.

GENTILE, M., 1986. El "control vertical" en el Noroeste Argentino. Notas sobre los atacamas en el valle calchaquí. Casimiro Quirós Editor, Buenos Aires.

GUNDERMANN, H., R. FOERSTERy J. I. VERGARA, 2003.Mapuche y aymara. El debate en torno al reconocimiento y los derechos ciudadanos. PREDES-RIL Editores, Santiago.

HIDALGO, J., 1978. Incidencias de los patrones de poblamiento en el cálculo de la población del Partido de Atacama desde 1752 a 1804. Las revisitas inéditas de 1787-1792 y 1804 . Estudios Atacameños 6: 53-111.

1985. Ecological complementarity and tribute in Atacama: 1683-1792. En Andean ecology and civilization, S. Masuda, I. Shimada y C. Morris (Eds.), pp. 161-184. University of Tokyo Press, Tokio.

2004. Historia andina en Chile. Editorial Universitaria, Santiago.

LEHNERT, R., 1981-82. Presencia del runa-simi en el sector atacameño. Cuadernos de Filología 15-16:29-47.
MANRÍQUEZ, V., 1999-2000. Proposiciones sobre la existencia de "identidad" o "identidades" en la localidad colonial de Caspana. Un acercamiento desde los archivos parroquiales. Revista de Historia Indígena 4: 103- 125.

MARTÍNEZ, J. L., 1985. La formación del actual pueblo de Toconce, s. XX. Chungara 15: 99-124.

1994. Relaciones y negociaciones entre las sociedades indígenas de la región atacameña, el Estado y la sociedad chilenos, s. XIX y XX. Proposiciones 24: 201-207.

1998. Pueblos del chañar y el algarrobo. Los atacamas en el s. XVII. DIBAM - Facultad de Filosofía y Humanidades Universidad de Chile, Santiago.

2009. Discursos coloniales e identidades étnicas. Los lipes en el s. XVI. Pontificia Universidad Católica del Perú, Centro Barros Arana, Dirección de Bibliotecas, Archivos y Museos, Lima, Santiago.

MARTÍNEZ, J. L., A. M. FARÍAS, V. MANRÍQUEZ y C. SANHUEZA, 1991. Interetnicidad y complementariedad: Dinámicas de las estrategias de supervivencia de los atacameños en el s. XVII. Histórica XV (1): 27-42.

MARTÍNEZ, R., 1994. Musique du désordre, musique de l'ordre. Le calendrier musical chez les jalq'a (Bolivie). Thèse présentée en vue du grade de Docteur en Ethnologie, Université de Paris X, Nanterre.

1996a. Flûtes de pan et modernité dans les Andes. L' example jalq'a. Cahiers de Musiques Traditionelles 9: 225-239.

1996b. El sajjra en la música de los jalq’a. En Cosmología y música en los Andes, M. Baumann (Ed.), pp. 311-322. Bibliotheca IberoAmericana, vol. 55, Frankfurt.

MERCADO, C., J. L. RODRÍGUEZ y P. MIRANDA, 1997. Pa' que coman las almas. La muerte en el Alto Loa. LOM Ediciones, Santiago.

MOLINIÉ, A., 1997. Buscando una historicidad andina: Una propuesta antropológica y una memoria hecha rito. En Arqueología, antropología e historia en los Andes. Homenaje a María Rostworowski. R. Varon y J. Flores (Eds.), pp. 691-708. Instituto de Estudios Peruanos, Banco Central de Reserva del Perú, Lima.

PEASE, F., 1977. Collaguas: una etnía del s. XVI. Problemas iniciales. En Collaguas I, F. Pease (Ed.), pp. 131-167. Universidad Católica del Perú, Lima.

SANHUEZA, C., 1992. Estrategias readaptativas en Atacama: La arriería mulera colonial. En Etnicidad, economía y simbolismo en Los Andes, S. Arze, R. Barragán, L. Escoban y X. Medinacelli 
(Comps.), pp. 363-385. HISBOL-Instituto Francés de Estudios Andinos-SBH, La Paz.

2001. Las poblaciones de la Puna de Atacama y su relación con los Estados nacionales. Una lectura desde el archivo. Revista de Historia Indígena 5: 55-82.

URIBE, M., 1997. La alfarería de Caspana en relación a la prehistoria tardía de la subárea Circumpuneña. Estudios Atacameños 14: 243262.

VILCAPOMA, J. C., 2006. Tradición oral de Parinacochas. De gentiles, incas y cristos del camino. Pacarina 1: 38-54.

WACHTEL, N., 1974. Le dualisme chipaya. Compte-rendu de Mission. Bulletin de l'Institut Français d'Études Andins 3 (3):55-65.
1978. Hommes d'eau: Le problème uru (XVIe-XVIIe siècles). Annales E.S.C. Numéro spécial (5-6): 1127-1159.

1990. Le retour des ancêtres. Les indiens urus de Bolivie, XX-XVI siècle. Essai d'Histoire régressive. Editions Gallimard, París.

1992. Note sur le problème des identités collectives dans les Andes Méridionales. L'Homme 122-124:39-52.

WEISCHERT, W., 1975. Las condiciones climáticas del desierto de Atacama como desierto extremo de la tierra. Norte Grande 3-4: 363-373. 